\title{
Effectiveness of training health professionals to provide smoking cessation interventions: systematic review of randomised controlled trials
}

\author{
Christopher Silagy, Tim Lancaster, Stephen Gray, Godfrey Fowler
}

\begin{abstract}
Objective-To assess the effectiveness of interventions that train healthcare professionals in methods for improving the quality of care delivered to patients who smoke.

Design-Systematic literature review.

Setting-Primary care medical and dental practices in the United States and Canada. Patients were recruited opportunistically.

Subjects-878 healthcare professionals and 11228 patients who smoked and were identified in eight randomised controlled trials. In each of these trials healthcare professionals received formal training in smoking cessation, and their performance was compared with that of a control group.

Main measures-Point prevalence rates of abstinence from smoking at six or 12 months in patients who were smokers at baseline. Rates of performance of tasks of smoking cessation by healthcare professionals, including offering counselling, setting dates to stop smoking, giving follow up appointments, distributing self help materials, and recommending nicotine gum.
\end{abstract}

Methods-Trials were identified by multiple methods. Data were abstracted according to predetermined criteria by two observers. When possible, metaanalysis was performed using a fixed effects model and the results were subjected to sensitivity analysis.

Flinders University of South Australia School of Medicine, Adelaide, Australia Christopher Silagy, professor of general practice

Imperial Cancer Research Fund General Practice Research Group, University Department of Public Health and Primary Care, Radcliffe Infirmary, Gibson Building, Oxford OX2 6HE

Tim Lancaster, deputy director Stephen Gray, research

officer

Godfrey Fowler, honorary director and reader in general practice

Correspondence to: Dr Lancaster

Accepted for publication 30 September 1994
Results-Healthcare professionals who had received training were significantly more likely to perform tasks of smoking cessation than untrained controls. There was a modest increase in the odds of stopping smoking for smokers attending health professionals who had received training compared with patients attending control practitioners (odds ratio $1 \cdot 35(95 \%$ confidence interval 1.09 to 1.68$)$ ). This result was not robust to sensitivity analysis. The effects of training were increased if prompts and reminders were for more intensive forms of counselling compared with minimal contact strategies. Conclusions-Training health professionals to provide smoking cessation interventions had a measurable impact on professional performance. A modest, but non-robust, effect on patient outcome was used. There was no definite benefit found also found, suggesting that training alone is unlikely to be an effective strategy for improving quality of care, unless organisational and other factors are also considered.

(Quality in Health Care 1994;3:193-198)

\section{Introduction}

Decreasing the prevalence of smoking is a public health priority in most Western societies, ${ }^{1}$ although there is considerable debate about the methods by which this is best achieved. ${ }^{2}$ Population strategies, including legislation to prevent tobacco advertising, higher taxation, and restriction of smoking in public areas all have an important role. However, healthcare professionals are also in a position to contribute to achieving national targets for reducing smoking in the population.

There is substantial evidence that the advice and support given to smokers by healthcare professionals in primary care settings can achieve abstinence rates of between $5 \%$ and $10 \%$ with minimal intervention programmes and between $15 \%$ and $30 \%$ with more intense interventions. ${ }^{3}$ Although many clinicians will find these rates low, they could translate into a substantial public health benefit if consistently provided, as approximately $80 \%$ of adults have contact with a healthcare practitioner, usually in primary care, at least once each year. ${ }^{4}$ It is disappointing, therefore, that the number of patients who report receiving advice on how to stop smoking from health professionals is low. ${ }^{4}$ Increasing the amount and quality of interventions from primary care health professionals is frequently cited as a way of realising this potential health gain. ${ }^{6}$ Providing training in smoking cessation is one possible method for doing this, and various courses and methods are available. However, whereas individual studies have shown that training affects doctors' activities, there has been doubt about the extent to which this translates into changes in patients' behaviour. $^{7-9}$

We addressed this issue by systematically identifying and quantitatively reviewing the evidence from randomised controlled trials that have studied the effects of training healthcare professionals to provide advice about smoking cessation and supporting them in doing so. We hypothesised (a) that training healthcare professionals is more effective than no training in increasing the number of smokers who are offered advice about stopping 
and who subsequently achieve abstinence and (b) that the effect of training can be enhanced by either providing prompts and reminders to healthcare professionals to offer advice about smoking cessation to their patients or encouraging them to offer nicotine replacement therapy as an adjunct to their advice to smokers.

\section{Methods}

We conducted a computerised literature search using the Datastar system on seven electronic databases to identify trials of smoking cessation that had been published before August 1993. The terms used in the search strategy (which varied slightly depending on the particular database) were (a) smoking and (b) smoking cessation in combination with randomized controlled trial or prospective or random allocation or double blind method. We also examined published reviews, reference lists from clinical trials, conference abstracts, smoking and health bulletins, and the bibliography on smoking and health. To identify unpublished studies, letters were sent to all investigators who had previously published a trial of smoking cessation.

We inspected each of the trials identified by these methods to find those that addressed the effectiveness of training healthcare professionals in promoting smoking cessation. To be included in the meta-analysis studies had to have allocated healthcare professionals to at least two groups by a formal randomisation process. Studies that used historical controls were excluded.

We considered two types of patient outcome measure. The first were process variables, which included the number of smokers who were counselled, asked to set a date for stopping (quit date), given a follow up appointment, given self help materials, offered nicotine gum, or prescribed a quit date. The second were rates of abstinence from smoking. We included the second outcome measure only if the abstinence rates provided were six months or more since the start of the intervention. The strictest available criteria to define abstinence were used. In studies where biochemical validation of cessation was available, only those subjects who met the criteria for biochemically confirmed abstinence were regarded as being abstinent. Point prevalence abstinence rates were taken as the primary outcome. Participants lost to follow up were regarded as being continuing smokers.

Data were extracted from the published reports by two people independently (CS, SG). Disagreements were resolved by referral to another person. No attempt was made to blind any of these people either to the results of the primary studies or to the intervention the subjects received.

The methodological quality of the studies included in the review was assessed by the simplified scheme described by Chalmers et al. ${ }^{10}$ Briefly, this scores three facets of trial methods that are potential sources of bias. These are (a) the quality of the random allocation (that is, control of selection bias at entry); (b) the extent to which the primary analysis included every person entered into the randomised cohorts (that is, control of selection bias after entry); and (c) the extent to which those assessing outcome were unaware of the group assignment of the individuals being examined (that is, control of bias in assessing outcome). For each of the three facets we used a three point rating scale (a score of 3 meant that the effort to control potential bias had been maximal and a score of 1 that there had been little or no attempt to control potential bias).

The statistical methods used to pool the data entailed calculating the typical odds ratio and its confidence interval based on a fixed effects model as described by Yusuf et al. ${ }^{11}$ Before combining results, we tested for heterogeneity. ${ }^{12}$ Sensitivity analyses were performed to assess the robustness of the pooled results and to explore heterogeneity when this was detected. In examining the effects of training, results are expressed as odds ratios (training:no training) with $95 \%$ confidence intervals. In some trials training was compared not only with non-intervention controls, but also with another non-training intervention. For example, in one trial trained physicians were compared with a normal care control group and with a non-trained group who were asked to offer nicotine gum. ${ }^{13}$ Provided that there were no significant differences in outcome between the non-training interventions, they were pooled to act as the control group in the comparison with the effects of training. To examine the incremental effects of prompts and of nicotine gum we considered trials in which the effects of these strategies combined with training were compared with training alone.

\section{Results}

DESCRIPTION OF TRIALS

A total of 12 published trial reports ${ }^{7-9}{ }^{13-21}$ were considered for inclusion in the review. Of these, two were excluded because the relevant results from the trials they described were available in the other references. ${ }^{2021}$ Two more were excluded because they did not meet our inclusion criteria. One study, which compared academic detailing, courier delivery, and direct mailing of a new smoking cessation programme designed for use in primary care, did not include any measure of the extent to which physicians changed their counselling or the number of smokers who stopped smoking in the three groups. ${ }^{14}$ The other was a study of training residents in obstetrics and family practice to give advice about stopping smoking during prenatal care, but training was not the variable that was randomised. ${ }^{15}$ Table 1 shows the characteristics of the eight trials which met our inclusion criteria, including our ratings of the quality of their methods.

In seven of the eight studies included the healthcare practitioner was the principal unit of randomisation..$^{791316171920}$ In the remaining trial physicians received training in a brief contact strategy and in more extensive patient centred counselling, and they delivered the 
Table 1 Characteristics of trials reviewed

\begin{tabular}{|c|c|c|c|c|c|c|c|c|c|c|}
\hline Reference & $\begin{array}{l}\text { Type of physician/ } \\
\text { setting of care }\end{array}$ & $\begin{array}{l}\text { Comparison groups } \\
\text { and content of training }\end{array}$ & $\begin{array}{l}\text { Type of } \\
\text { training }\end{array}$ & $\begin{array}{c}\text { No of } \\
\text { healthcare } \\
\text { professionals }\end{array}$ & $\begin{array}{c}\text { No of } \\
\text { patients }\end{array}$ & $\begin{array}{l}\text { Follow up } \\
\text { (months) }\end{array}$ & $\begin{array}{c}\text { Validation of } \\
\text { point prevalence } \\
\text { (abstinence outcome) }\end{array}$ & $\begin{array}{l}\text { Control } \\
\text { of bias } \\
\text { at entry }\end{array}$ & $\begin{array}{l}\text { Control } \\
\text { of bias } \\
\text { after } \\
\text { entry }\end{array}$ & $\begin{array}{l}\text { Control } \\
\text { of bias in } \\
\text { outcome } \\
\text { assessment }\end{array}$ \\
\hline $\begin{array}{l}\text { Wilson et al } \\
1988^{13}\end{array}$ & $\begin{array}{l}\text { Canadian private } \\
\text { family practice }\end{array}$ & $\begin{array}{l}1 \text { Normal care } \\
2 \text { Nictotine gum and advice } \\
3 \text { Nictotine gum plus training } \\
\text { (use of gum, quit dates, } \\
1-6 \text { follow up visits) }\end{array}$ & $\begin{array}{l}\text { Tutorial } \\
\text { (group), } \\
4 \text { hours }\end{array}$ & 83 & 1933 & 12 & $\begin{array}{l}\text { Salivary cotinine/ } \\
\text { thiocyanate }\end{array}$ & 2 & 3 & 3 \\
\hline $\begin{array}{l}\text { Cohen et al } \\
1989^{17}\end{array}$ & $\begin{array}{l}\text { American private } \\
\text { primary care } \\
\text { medical practice }\end{array}$ & $\begin{array}{l}1 \text { Training (advice, quit date, } \\
\text { follow up check) } \\
2 \text { Training and prompt } \\
3 \text { Training and nicotine gum } \\
4 \text { Training, prompt, and } \\
\text { nictotine gum }\end{array}$ & $\begin{array}{l}\text { Tutorial } \\
\text { (group), } \\
1 \text { hour }\end{array}$ & 114 & 1420 & 12 & Expired carbon monoxide & 2 & 3 & 3 \\
\hline $\begin{array}{l}\text { Cohen et al } \\
1989^{16}\end{array}$ & $\begin{array}{l}\text { American private } \\
\text { dental practice }\end{array}$ & $\begin{array}{l}1 \text { Training (advice, quit date, } \\
\text { follow up check) } \\
2 \text { Training and prompt } \\
3 \text { Training and nicotine gum } \\
4 \text { Training, prompt, and } \\
\text { nicotine gum }\end{array}$ & $\begin{array}{l}\text { Tutorial } \\
\text { (group), } \\
1 \text { hour }\end{array}$ & 44 & 1027 & 12 & Expired carbon monoxide & 2 & 3 & 3 \\
\hline $\begin{array}{l}\text { Cummings } \\
\text { et al } 1989^{9}\end{array}$ & $\begin{array}{l}\text { American primary } \\
\text { care medical } \\
\text { practice (health } \\
\text { maintenance } \\
\text { organisation) }\end{array}$ & $\begin{array}{l}1 \text { Normal care } \\
2 \text { Training (personalised } \\
\text { advice, quit date, one follow } \\
\text { up visit, self help materials, } \\
\text { nicotine gum) }\end{array}$ & $\begin{array}{l}\text { Tutorial } \\
\text { (group), } \\
3 \times 1 \text { hour }\end{array}$ & 81 & 2056 & 12 & $\begin{array}{l}\text { Expired carbon monoxide, } \\
\text { serum cotinine }\end{array}$ & 3 & 3 & 3 \\
\hline $\begin{array}{l}\text { Cummings } \\
\text { et al } 1989^{8}\end{array}$ & $\begin{array}{l}\text { American private } \\
\text { primary care } \\
\text { medical practice }\end{array}$ & $\begin{array}{l}1 \text { Normal care } \\
2 \text { Training (personalised } \\
\text { advice, quit date, one follow } \\
\text { up visit, self help materials, } \\
\text { nicotine gum) }\end{array}$ & $\begin{array}{l}\text { Tutorial } \\
\text { (group), } \\
3 \times 1 \text { hour }\end{array}$ & 44 & 916 & 12 & $\begin{array}{l}\text { Expired carbon monoxide, } \\
\text { serum cotinine }\end{array}$ & 3 & 3 & 3 \\
\hline $\begin{array}{l}\text { Kottke } \text { et al } \\
1989^{7}\end{array}$ & $\begin{array}{l}\text { American private } \\
\text { primary care } \\
\text { medical practice }\end{array}$ & $\begin{array}{l}1 \text { Normal care } \\
2 \text { Self help materials } \\
3 \text { Training (personalised } \\
\text { advice, quit date, nicotine } \\
\text { gum, self help materials, } \\
\text { follow up) }\end{array}$ & $\begin{array}{l}\text { Tutorial } \\
\text { (group), } \\
6 \text { hours }\end{array}$ & 66 & 1653 & 12 & Serum cotinine & 2 & 3 & 3 \\
\hline $\begin{array}{l}\text { Ockene et al } \\
1991^{18}\end{array}$ & $\begin{array}{l}\text { American primary } \\
\text { care residency } \\
\text { training } \\
\text { programme }\end{array}$ & $\begin{array}{l}1 \text { Training (advice) } \\
2 \text { Training (patient centred } \\
\text { counselling) } \\
3 \text { Training (counselling and } \\
\text { nicotine gum) plus } \\
\text { minimal or intensive follow } \\
\text { up telephone contact }\end{array}$ & $\begin{array}{l}\text { Tutorial } \\
\text { (group), } \\
21 / 2 \text { hours }\end{array}$ & 196 & 1286 & 6 & Self report & 3 & 3 & 2 \\
\hline $\begin{array}{l}\text { Strecher } \\
\quad \text { et al } 1991^{19}\end{array}$ & $\begin{array}{l}\text { American primary } \\
\text { care residency } \\
\text { training } \\
\text { programme }\end{array}$ & $\begin{array}{ll}1 & \text { Normal care } \\
2 & \text { Training (simple advice) } \\
3 & \text { Prompt } \\
4 & \text { Training and prompt }\end{array}$ & $\begin{array}{l}\text { Tutorial } \\
\text { (group), } \\
1 \text { hour }\end{array}$ & 250 & 937 & 6 & Expired carbon monoxide & 2 & 2 & 2 \\
\hline
\end{tabular}

$\star 3=$ Maximal effort to control potential bias; $1=$ little or no attempt to control bias.

interventions to individual patients according to a randomised schedule. No restriction was placed on the age or sex of smokers who subsequently consulted these practitioners.

Seven of the eight trials examined the effectiveness of training medical practitioners, ${ }^{7-9} 131^{18-20}$ and two were confined to junior medical staff..$^{18}{ }^{19}$ One trial examined the effectiveness of training dental practitioners. ${ }^{16}$ All of the trials were conducted in primary care settings and were directed towards opportunistic intervention. Because all the trials were conducted in North America, however, primary care encompassed a diversity of settings including community practice, hospital based clinics, and health maintenance organisations. A record of the number of physicians invited to take part in training programmes was maintained for five trials. In these, the participation rate ranged from less than $10 \%$ among private practitioners to $90 \%$ among members of a residency training programme.

In all cases the training provided was on a group basis in tutorials or workshops. The duration of training ranged from a single one hour session to a total of six hours. Several different training methods were incorporated in these sessions, including lectures, videos, role playing, and discussion. One trial evaluated intensive patient centred counselling, ${ }^{18}$ while the rest emphasised minimal contact strategies. The importance of setting quit dates and offering follow up was emphasised in most trials. In only one, however, was a specific follow up schedule (up to six appointments) recommended. ${ }^{13}$ Instruction on the use of nicotine gum was part of the training in four trials, and three trials examined its specific interaction with different forms of training.

All trials reported abstinence as the principal patient outcome. In two trials this was after six months of follow up; in the remainder it was after 12 months. Although some trials reported rates for sustained abstinence of more than three months, only the final estimate of point prevalence was supported by biochemical validation.

Five of the trials examined the effect of training on process variables in comparison with untrained control groups..$^{7-9} 1319$ In two trials all healthcare professionals received training, and the randomisation examined the effect of using prompts and nicotine gum, separately and combined, as enhancements to training. ${ }^{16}{ }^{17}$ Another trial also did not include an untrained control group, reporting comparisons between different intensities of counselling. ${ }^{18}$ 


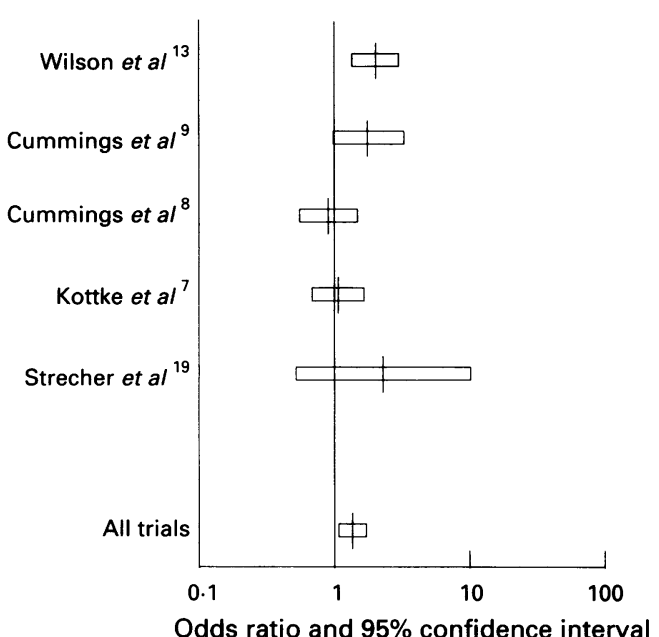

Effect of training on abstinence rates

METHODOLOGICAL OUALITY

The trials generally achieved good quality scores. All the trials scored highly on control of bias after entry because they included patients lost to follow up in their analysis of efficacy, assuming them to be continuing smokers. Seven of the eight trials controlled for bias in outcome assessment by biochemically validating self reports of abstinence. Most variation occurred in the control of selection bias at entry: only three trials specified the procedure used in randomisation.

EFFECT OF TRAINING ON ABSTINENCE RATES The effects of training on abstinence rates are shown in the figure and the data are given in tables 2 and 3. Smokers offered advice by health professionals who had received training in smoking cessation methods had a significant increase in their odds of stopping compared

Table 2 Effect of providing training on smoking cessation to healthcare professionals

\begin{tabular}{|c|c|c|c|c|c|}
\hline \multirow[t]{2}{*}{ Reference } & \multicolumn{2}{|c|}{ Training } & \multicolumn{2}{|c|}{ No training } & \multirow{2}{*}{$\begin{array}{c}\text { Odds ratio } \\
\text { (95\% confidence interval) }\end{array}$} \\
\hline & Observed & Total & Observed & Total & \\
\hline 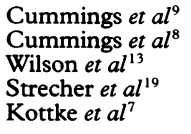 & $\begin{array}{r}26 \\
31 \\
55 \\
5 \\
36\end{array}$ & $\begin{array}{r}1024 \\
470 \\
606 \\
234 \\
660\end{array}$ & $\begin{array}{r}15 \\
36 \\
67 \\
2 \\
52\end{array}$ & $\begin{array}{r}1032 \\
496 \\
1327 \\
225 \\
993\end{array}$ & $\begin{array}{l}1.74(0.04 \text { to } 3.23) \\
0.90(0.55 \text { to } 1.48) \\
1.98(1.33 \text { to } 2.93) \\
2.29(0.52 \text { to } 10.18) \\
1.04(0.67 \text { to } 1.62)\end{array}$ \\
\hline Total & & & & & $1.35(1.09$ to 1.62$)$ \\
\hline
\end{tabular}

Table 3 Effect of different strategies in addition to training on smoking cessation

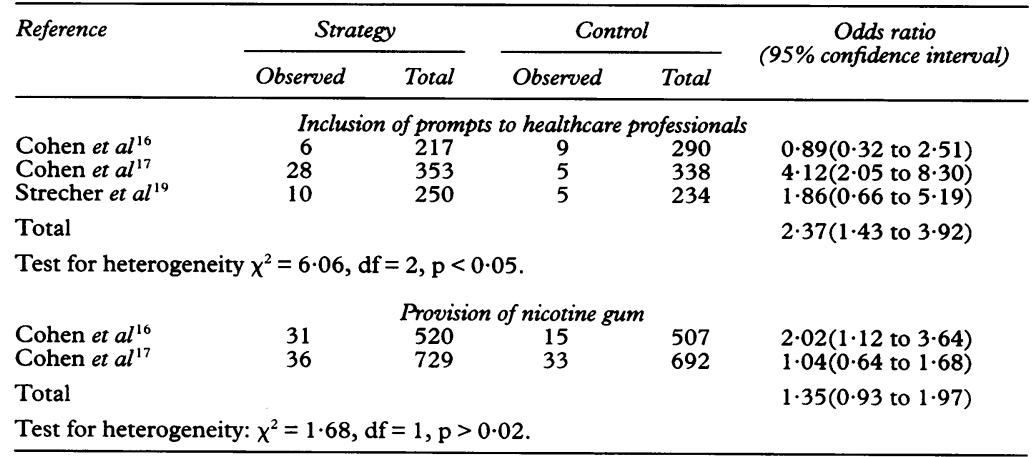

with smokers who attended control practitioners (odds ratio $1.35(95 \%$ confidence interval 1.09 to 1.68$)$ ). There was no significant heterogeneity detected in this analysis. The conclusion that training improves patient outcome was, however, highly sensitive to the findings of one study, ${ }^{13}$ and when this study was excluded the improvement in patient outcome was no longer significant (odds ratio $1 \cdot 10(0 \cdot 83$ to $1 \cdot 40))$.

\section{EFFECT OF ADJUNCTS TO TRAINING ON} ABSTINENCE

The odds of quitting were increased if prompts and reminders to practitioners to use smoking cessation techniques were used in addition to a training programme (odds ratio $2 \cdot 37(1.43$ to 3.92)), although these data are derived from only three trials. In contrast, when nicotine gum was provided in addition to brief contact training the odds of smokers quitting also increased, but the number of subjects was too few for this to reach significance.

EFFECT OF TYPE OF COUNSELLING

One trial compared the effects of training physicians to provide patient centred counselling, with or without nicotine gum, with training in giving simple advice alone. ${ }^{18}$ When taken together, the two counselling arms resulted in six month self reported point prevalence smoking cessation rates that were significantly better than simple advice (odds ratio $1.65(1.16$ to $2 \cdot 34)$ ). However, there was no significant difference in outcome when patient centred counselling without nicotine gum was compared with simple advice. Smokers who received patient centred counselling were more likely to rate their physician as having been helpful in supporting their trying to stop smoking. This trial also examined the additional impact of telephone follow up by counsellors as an adjunct to the physician intervention, finding no additional benefit from this intervention.

EFFECTS OF TRAINING ON PROCESS VARIABLES Table 4 shows the effect of training on professional activities. There was a clear increase in the odds of receiving some form of counselling, being set or prescribed a quit date, having a follow up appointment suggested, and receiving self help materials or nicotine gum if the smoker attended a healthcare professional who had received training in smoking cessation. There was significant statistical heterogeneity detected in these analyses, so the pooled odds ratios must be interpreted with caution. Sensitivity analysis indicated that most of the heterogeneity was attributable to one study, ${ }^{13}$ which reported strongly positive effects from training. When we removed this study from the analysis, however, the direction of the effect did not change, only its size. For example, the odds ratio for the effect of training on the number of patients counselled dropped from 1.44(1.29 to 1.60$)$ to $1.41(1.26$ to 1.58$)$ when this study was excluded. The conclusion that training improves the performance of physician activities is therefore robust. 


\section{Discussion}

Programmes designed to train health professionals to provide smoking cessation intervention are clearly effective in increasing a number of intermediate outcomes, including the number of patients who receive counselling, set a quit date, and are given follow up appointments, self help materials, and nicotine gum.

The more important issue is how effective they are in stopping patients smoking. Our pooled results suggest that there is a modest, but significant, effect on this outcome. This result depends heavily, however, on the results of one trial, which also reported more favourable effects on process than any other study. ${ }^{13}$ This discrepancy is unlikely to be the result of methodological weaknesses as this study achieved high quality ratings by our scoring system. A more likely explanation is the nature of the intervention. The training in this study emphasised the importance of follow up to a far greater degree than any of the other programmes studied. Physicians were trained to challenge the patient at a first appointment, to schedule a separate appointment to set a quit date, and to offer up to four supportive

Table 4 Effect of providing training on smoking cessation to healthcare professionals

\begin{tabular}{|c|c|c|c|c|c|}
\hline \multirow[t]{2}{*}{ Reference } & \multicolumn{2}{|c|}{ Training } & \multicolumn{2}{|c|}{ No training } & \multirow{2}{*}{$\begin{array}{c}\text { Odds ratio } \\
\text { (95\% confidence interval) }\end{array}$} \\
\hline & Observed & Total & Observed & Total & \\
\hline \multicolumn{6}{|c|}{ On No of patients counselled } \\
\hline Wilson et $a l^{13}$ & 82 & 96 & 94 & 184 & $4.33(2.60$ to $7 \cdot 21)$ \\
\hline Cummings et $a l^{9}$ & 471 & 1024 & 423 & 1032 & $1.23(1.03$ to 1.46$)$ \\
\hline Cummings et al ${ }^{8}$ & 265 & 470 & 181 & 446 & $1.88(1.45$ to 2.44$)$ \\
\hline Kottke $\mathrm{et} \mathrm{al}^{7}$ & 358 & 660 & 485 & 993 & $1.24(1.02$ to 1.51$)$ \\
\hline Strecher et al ${ }^{19}$ & 183 & 234 & 155 & 225 & $1.61(1.07$ to 2.44$)$ \\
\hline Total & & & & & $1.44(1.29$ to 1.60$)$ \\
\hline
\end{tabular}

Test for heterogeneity: $\chi^{2}=27 \cdot 75, \mathrm{df}=4, \mathrm{p}=<0 \cdot 001$

\begin{tabular}{lrrrr} 
& \multicolumn{4}{c}{ On asking smoker to set a quit date } \\
Wilson et al $^{13}$ & 52 & 96 & 13 & 184 \\
Cummings et $_{\text {al }}{ }^{8}$ & 100 & 470 & 22 & 446 \\
Cummings al $^{8}$ & 385 & 1024 & 115 & 1036 \\
Kottke et $^{7}{ }^{7}$ & 358 & 660 & 485 & 993 \\
Strecher et $^{19}{ }^{19}$ & 21 & 234 & 14 & 225
\end{tabular}

$13.91(7 \cdot 76$ to $24 \cdot 94)$ $4 \cdot 11(2 \cdot 81$ to $6 \cdot 02)$ $4 \cdot 22(3.45$ to $5 \cdot 17)$ $1 \cdot 24(1 \cdot 02$ to $1 \cdot 51)$ $1 \cdot 48(0 \cdot 74$ to $2 \cdot 94)$ $2 \cdot 59(2 \cdot 28$ to $2 \cdot 94)$

Total

Test for heterogeneity: $\chi^{2}=116 \cdot 40, \mathrm{df}=4, \mathrm{p}=<0 \cdot 001$.

Wilson et al ${ }^{13}$ Cummings et $a l^{9}$ Cummings et al Kottke et al

Strecher et al $^{19}$

$\begin{array}{rcr} & \text { On making a follow up } \\ 80 & 96 & 25 \\ 50 & 470 & 19 \\ 156 & 1024 & 52 \\ 68 & 660 & 56\end{array}$

Total

1036
993

ment

446

234

Test for heterogeneity: $\chi^{2}=95 \cdot 34, \mathrm{df}=4, \mathrm{p}=<0 \cdot 001$.

\begin{tabular}{lrrrr} 
& \multicolumn{4}{c}{ On handing out self help materials } \\
Wilson et al $^{13}$ & 77 & 96 & 18 & 184 \\
Cummings et $_{\text {al }}$ & 151 & 470 & 38 & 446 \\
Kottke et $^{9} l^{7}$ & 224 & 660 & 258 & 993 \\
Strecher et $_{\text {al }}{ }^{19}$ & 23 & 234 & 29 & 225
\end{tabular}

Total

Test for heterogeneity: $\chi^{2}=119 \cdot 92, \mathrm{df}=3, \mathrm{p}=<0.001$.

Wilson et al ${ }^{13}$

Wilson et $a l^{13}$ et $a l^{9}$
Cummings et $a l^{8}$

Strecher et al ${ }^{19}$

Total

\begin{tabular}{rcrr}
\multicolumn{4}{c}{ On offering smokers nicotine gum } \\
60 & 96 & 63 & 184 \\
104 & 1024 & 108 & 1036 \\
34 & 470 & 34 & 446 \\
40 & 234 & 29 & 225
\end{tabular}

\section{4}

1036
446
225

$8.95(4.88$ to 16.43$)$

$0.97(0.73$ to 1.29$)$
$0.94(0.58$ to 1.55$)$

$1.39(0.83$ to 2.32$)$

$1.24(1.02$ to 1.52$)$

Test for heterogeneity: $\chi^{2}=17 \cdot 63, \mathrm{df}=3, \mathrm{p}=<0.001$.

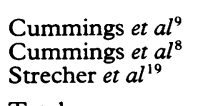

\begin{tabular}{rccr}
\multicolumn{4}{c}{ On prescribing a quit date } \\
165 & 1024 & 12 & 1036 \\
44 & 470 & 2 & 446 \\
14 & 234 & 5 & 225
\end{tabular}

Total

Test for heterogeneity: $x^{2}=3 \cdot 79, \mathrm{df}=2, \mathrm{p}=0 \cdot 15$. follow up visits. Moreover, the physicians were paid per item for each of these follow up visits according to the standard reimbursement scheme in the Canadian healthcare system. Although in most of the trials some form of follow up was recommended as part of the training, in none of the others was a specific schedule arranged, and few such visits were scheduled. This may be related to the fact that reimbursement for such visits is generally not forthcoming from third party payers in the United States, where all the remaining studies took place. The implication of these findings is that training alone is unlikely to represent a useful investment of resources, unless it is linked to organisational changes that facilitate the intervention. This is consistent with a recent review of 50 randomised controlled trials covering a wide range of subjects and types of intervention. ${ }^{22}$ The review found that educational strategies that helped practice and were reinforced by follow up and reminders were major determinants of successful continuing medical education. ${ }^{22}$

This conclusion is particularly relevant in considering the generalisability of these results to primary care within the British national health service. Preventive activities must compete with other pressing demands on general practitioners. Intensive strategies that entail multiple follow up visits may make unrealistic demands on limited clinical time. Team approaches, in which the tasks of smoking cessation are shared between different health professionals (general practitioners and practice nurses, for example), is one possible solution to this problem. ${ }^{23}$ Our results show that adjuncts such as manual or computerised reminders to provide advice on smoking are effective and should form part of such strategies. Similarly, although we were unable to show a conclusive benefit from adding nicotine gum to training, it is clear from other work that nicotine replacement can improve the chances of stopping smoking in some patients ${ }^{24}$ and should play an integral part in smoking cessation programmes in primary care.

The studies we reviewed give limited information about the relative efficacy of different approaches to counselling smokers. Behavioural scientists often argue that simple advice alone is ineffective in promoting sufficient change in behaviour, and more intensive training in counselling methods, such as motivational interviewing, ${ }^{25}$ might lead to higher success rates. However, in the one trial that compared provision of advice by trained physicians with provision of patient centred counselling, also by trained physicians, there was no significant difference in the self reported quit rates at six months, unless nicotine gum was included with counselling. ${ }^{18}$ Caution is required in interpreting this finding as it was derived from only one trial, which had limited power to detect a small effect, and further research is needed.

A further reason why the effects of training seen in this review seems to be limited is that the use of "quitting" as a patient based outcome may be inappropriate for this type of 
study. Support for this stems from recent theories of how patients change their smoking behaviour. Prochaska and DiClemente have proposed a model of different "stages of readiness" leading to behavioural change. ${ }^{26}$ In this model, smoking cessation is seen as a process with several discrete stages of readiness to change. It would be unrealistic to expect someone who is at a "pre-contemplative phase" to stop smoking within a short period of time as a result of contact with a physician. A more appropriate patient based outcome measure might be whether the intervention helps such a person to move to the next stage, where they are ready to "contemplate" stopping. None of the trials we studied considered this outcome. Simple rating scales that assess readiness to change now exist, ${ }^{27}$ and it will be important to examine their utility as outcome measures in future trials of smoking cessation.

Several methodological limitations of this meta-analysis need to be borne in mind. The analysis was based on tabulated data available in published reports rather than data on individual patients, which may lead to problems associated with publication bias, exclusion of patients, and length of follow up of patients. ${ }^{28}$ In addition, all but one of the studies related to training physicians. In the future, studies are needed which examine the effectiveness of training other types of healthcare professional who may also be in a position to provide counselling about stopping smoking. Nurses, pharmacists, and physiotherapists are all well placed to facilitate smoking cessation. In addition, given the importance we have attached in our conclusions to organisational and fiscal factors in supporting training interventions, training programmes which take specific account of the circumstances of the setting of care, such as British general practice, require evaluation. Training can be expensive, and simply providing programmes for healthcare professionals, without addressing the constraints imposed by the conditions in which they practise, is unlikely to be a wise use of healthcare resources.

1 Secretary of State for Health. The health of the nation: a strategy for health in England. London: HMSO, 1992. a strategy for

2 Chapman S. The role of doctors in promoting smoking cessation. BMF 1993;307:518-9.

3 Kottke TE, Battista RN, DeFriese GH, Brekke ML. Attributes of successful smoking cessation interventions in medical practice. A meta-analysis of 39 controlled trials. $\mathcal{f} A M A$ 1988;259:2883-9.
4 Silagy C, Muir J, Coulter A, Thorogood M, Yudkin P, Roe L. Lifestyle advice in general practice: rates recalled by patients. BMF 1992;305:871-4.

5 Wallace PG, Brennan PJ, Haines AP. Are general practitioners doing enough to promote healthy lifestyle? Findings of the Medical Research Council's general practice framework study on lifestyle and health. $B M$ 1987;294:940-2.

6 Sanders D. Smoking cessation interventions: is patien education effective? London: Department of Public Health and Policy, London School of Hygiene and Tropical and Policy, London

7 Kottke TE, Brekke ML, Solberg LI, Hughes JR. A randomized trial to increase smoking intervention by physicians. Doctors helping smokers, round I. $7 A M A$ 1989;261:2101-6.

8 Cummings SR, Richard RJ, Duncan CL, et al. Training physicians about smoking cessation: a controlled trial in private practice. f Gen Intern Med 1989;4:482-9.

9 Cummings SR, Coates TJ, Richard RJ, et al. Training physicians in counseling about smoking cessation. A randomized trial of the "Quit for Life" program. Anu Intern Med 1989;110:640-7.

10 Chalmers I, Enkin M, Keirse MJNC, eds. Effective care in pregnancy and childbirth. Vol 1. Oxford: Oxford University Press, 1988:46.

11 Yusuf S, Peto R, Lewis J, Collins R, Sleight P. Beta blockade during and after myocardial infarction: an overview of the randomized trials. Prog Cardiovasc Dis 1985;27:335-71.

12 Cochran WG. The combination of estimates from different experiments. Biometrics 1954;10:101-29.

13 Wilson DM, Taylor DW, Gilbert JR, et al. A randomized trial of a family physician intervention for smoking cessation. FAMA 1988;260:1570-4

14 Cockburn J, Ruth D, Silagy C, et al. Randomised trial of three approaches for marketing smoking cessation programmes to Australian general practitioners. $B M f$ 1992;304:691-4

15 Secker Walker RH, Solomon LJ, Flynn BS, et al. Training obstetric and family practice residents to give smoking cessation advice during prenatal care. Am $\mathcal{F}$ Obstet Gynecol 1992;166:1356-63.

16 Cohen SJ, Stookey GK, Katz BP, Drook CA, Christen AG. Helping smokers quit: a randomized controlled trial with private practice dentists. 7 Am Dent Assoc 1989;118:41-5.

17 Cohen SJ, Stookey GK, Katz BP, Drook CA, Smith DM. Encouraging primary care physicians to help smoker quit. A randomized, controlled trial. Ann Intern Med 1989;110:648-52

18 Ockene JK, Kristeller J, Goldberg R, et al. Increasing the efficacy of physician-delivered smoking interventions: a randomized clinical trial. 7 Gen Intern Med 1991;6:1-8.

19 Strecher VI, O'Malley MS, Villagra VG, et al Can residents be trained to counsel patients about quitting smoking? Results from a randomized trial 7 Gen Intem king? 1991;6:9-17.

20 Lindsay EA, Wilson DM, Gilbert JR. A randomized trial of physician training for smoking cessation. American foumal physician training for smoking ce
of Health Promotion 1989;3:11-8.

21 Campbell EE, Lyles MF, Strecher VJ, Gonzalez JJ. Teaching smoking cessation counseling skills to residen physicians. Clin Res 1989;37:80

22 Davis DA, Thomson MA, Oxman A, Haynes RB. Evidence for the effectiveness of CME. A review of 50 randomized controlled trials. $\mathcal{F} A M A$ 1992;268:1111-7.

23 Hollis JF, Lichtenstein E, Vogt TM, Stevens VJ, Biglan A Nurse-assisted counselling for smokers in primary care. Ann Intern Med 1993;118:521-5.

24 Silagy C, Mant D, Fowler G, Lodge M. Meta-analysis on efficacy of nicotine replacement therapies in smoking cessation. Lancet 1994;343:139-42.

25 Rollnick S, Kinnersley P, Stott N. Methods of helping patients with behaviour change. $B M \mathcal{F}$ 1993;307:188-90.

26 Prochaska JO, DiClemente CC. Stages and processes of self-change of smoking: toward an integrative model of self-change of smoking: toward an integrative

27 Owen N, Wakefield M, Roberts L, Esterman A. Stages of readiness to quit smoking: population prevalence and correlates. Health Psychol 1992;11:413-7.

28 Stewart LA, Parmar MK. Meta-analysis of the literature or of individual patient data: is there a difference? Lance 1993;341:418-22. 